\title{
Que Profissional Queremos Formar?
}

O mundo está em plena efervescência. Paradigmas científicos são rompidos, o desemprego aumenta, as pessoas adoecem no trabalho, mudam de carreira, enfim, vão se estruturando e sendo impactadas por estes novos processos produtivos. O objetivo da presente trabalho é discutir esses novos desafios postos à Psicologia por esse contexto de mudanças.

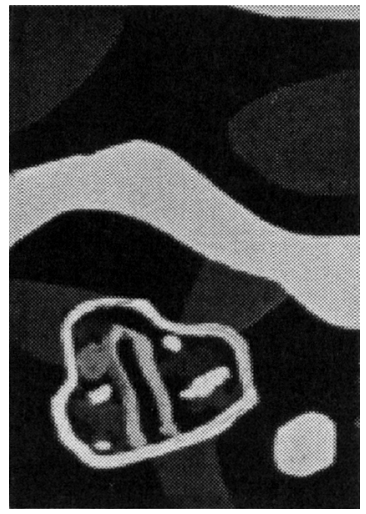

Maria Teresa Castelo Branco Professora assistente do Departamento de Psicologia da Universidade Federal do Paraná - UFPR: doutora em educaçãona Universidade Federal de Săo Carlos - UFSCar
A formação do psicólogo nos remete a três questões importantes: a realidade social que vem demandando a atuação deste profissional; a diversidade teórica e metodológica da psicologia; e a situação do ensino universitário no Brasil.

Não há como refletir sobre o profissional que se pretende formar sem se analisar a sociedade onde ele atuará, a atividade que exercerá e a agência que o educará. Cada um destes aspectos será analisado nas suas especificidades, mas eles se interpenetrarão, inevitavelmente, no decorrer da exposição do assunto.

\section{Realidade Social e Demanda pelo Trabalho do Psicólogo}

A sociedade brasileira apresenta, hoje, algumas características que devem ser consideradas na reflexão que pretendemos: 
no seu processo de produção social há uma divisão do trabalho que separa os indivíduos em classes que se apropriam desigualmente do produto do trabalho total. O conceito de classes não pressupõe grupos estanques de sujeitos, mas antagonismo e inter-dependência, em que uma classe só existe em oposiçăo a outra. As relações sociais são essencialmente heterogêneas, de dominação e conflituosas;

nāo pode ser analisada fora do contexto internacional, onde o Brasil tem mantido posição de subordinação econômica, social e cultural em relação ao grande capital;

separa trabalho intelectual de trabalho manual, como em qualquer sociedade capitalista, que provoca uma cisão no processo de conhecimento entre teoria e prática;

promove acesso insuficiente da maioria da população ao ensino formal;

sua história gerou uma experiência democrática frágil, com a participação política da classe trabalhadora constantemente cerceada, a sociedade civil se organizando lentamente, determinando uma consciência social mais facilmente ideologizada pelos meios de comunicação de massa;

apresenta uma das maiores taxas de mortalidade infantil do mundo e índices elevados de subnutrição e desnutrição;

trabalho infantil precoce, que aumenta a cada dia, e um número, também crescente, de crianças e adolescentes que vivem nas e das ruas;

formas institucionalizadas de violência cotidiana - contra a criança, os velhos, as mulheres, os negros, os homossexuais, os desabrigados, etc;

"quase cem milhōes de pessoas que vivem na pobreza. Destas, quase 60 milhōes sobrevivem em condições de miséria e nada menos do que 20 milhões em total indigência"2.

Buarque (1991, p.17) sintetiza tudo isto no seguinte texto:
"O Brasil mostra uma qualidade de vida pior à dos mais pobres países do mundo: violências sob todas as formas, mortalidade infantil, desnutrição, baixo nível de escolaridade, péssimas condições habitacionais, elevado grau de endividamento, aviltamento monetário, desarticulação social, corrupção, amplo processo de prostituição de todos os tipos, inclusive infantil, falta de solidariedade nacional, vandalismo, falta de confiança no futuro (...) A quase totalidade da população na miséria e uma minoria rica assustada. Uma sociedade violenta e instável em todos os aspectos. A pobreza não é um fenômeno novo. Mas agora ela é fabricada, como conseqüência das decisões de modernização. A crise urbana foi induzida pela ênfase na industrialização; a modernização agrícola agravou a fome; a desigualdade social deriva das decisões econômicas para viabilizar a modernização".

O quadro é de violência e miséria, porém, na medida que a sociedade é contraditória, mésmo que a exacerbação das desigualdades gere alternativas desagregadoras, infelicidade humana, perda da esperança, medo, massificação, enrijecimento dos valores, falta de reciprocidade, gera, também, formas de resistência cultural, de organizações populares, associações, sindicatos etc. Há sempre movimentos contra-hegemônicos, que permitem, apesar do instituído, que singularidades e espaços de autogestão coletiva se produzam, no trabalho cotidiano do instituinte.

Qual a demanda pelo psicólogo nesse cenário nacional? Pressupõe-se que a afetividade deva estar fluindo com dificuldade nas relações hierarquizadas experimentadas pelos indivíduos nos seus ambientes de trabalho, nas escolas, nas famílias, nos hospitais, nos meios de transporte, nas ruas etc. Porém, as instituições esperam comportamentos que mantenham um "equilíbrio" e uma produtividade adequada à reprodução das relações sociais de produção. Se a saúde mental for considerada como um estado de "bem-estar" de sujeitos singulares, conquistado nas suas relações objetivas, quem demandaria a atuação do psicólogo na sociedade? Quem definiria o que é "bemestar"? E em que situaçōes seria possivel ser sujeito, em uma sociedade que mercantiliza até as emoções?
1- Este texto foi apresentado em reunião pedagógica do departamento de Psicologia da UFPR, no ano de 1993 , com a finalidade de subsidiar discussöes sobre a reformulação curricular do curso de psicologia.

2. Dados do Núcleo de Estudos do Brasil Contemporâneo, do Centro de Estudos Avançados Multidisciplinares da UNB, In: Buarque, C. (1991). O Colapso da Modernidade Brasileira, Paz e Terra, Rio de Janeiro. 
Quem definiria o que

é "bem-estar"? E em que situações seria possivel ser sujeito. em uma sociedade que mercantiliza até as emoções?

3. Conforme o que demonstra a pesquisa In: Carvalho, C.V. \& Silva, L.C. da. (1990). Atuação dos Psicólogos na Saúde Pública. Psicologia, Ciência e Profissão, ñ 2, 3-4.
A concepção de saúde mental adotada por grande parte dos psicólogos isola o indivíduo de sua realidade histórico-social, considerando seus problemas como frutos de um funcionamento interno ou de um condicionamento externo. Demonstram uma visão dicotomizada da realidade que irá orientar suas práticas. Macedo $(1984$, p.13) chamou o modelo de atuação que advém dessas concepções de "clínico tradicional", no qual as atividades básicas são o diagnóstico, a terapia, o aconselhamento e oxame psicotécnico. A autora revela o sentido das demandas pelo trabalho do psicólogo no contexto das relações sociais:

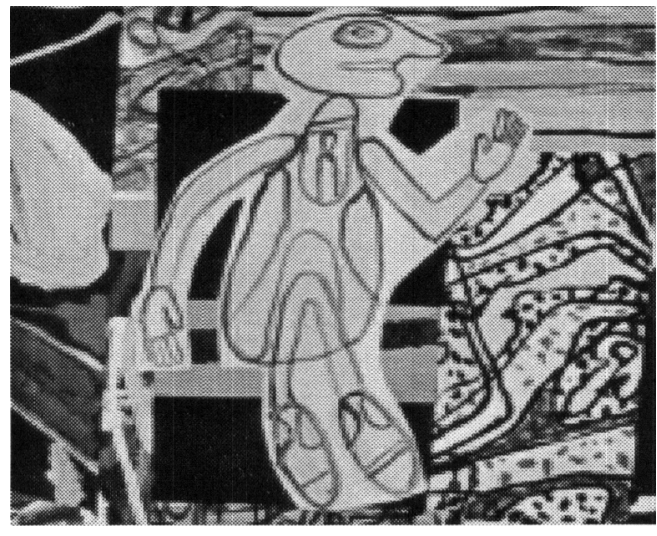

"temos de um lado as classes mais altas, 'intelectualizadas e narcisistas' (Monteiro, 1993) cuja demanda sempre maior por atendimento psicológico, principalmente terapêutico, reflete uma cultura em que a terapia seria uma saida viável para a resolução dos conflitos interiores causados por uma sociedade tecnológica, desafiadora, competitiva e destituída de espaço para trocas afetivas entre as pessoas, encerrando-as em si mesmas e na sua solidão; de outro lado temos as classes menos favorecidas, para as quais os problemas são conseqüências inevitáveis das circunstâncias externas para cuja resolução seria destituída de significado uma intervenção psicológica."

Na realidade, o tratamento psicológico é dirigido principalmente à burguesia nos consultórios particulares e às classes populares resta o atendimento psiquiátrico, como corretivo para o que é considerado um comportamento "anormal".
O trabalho de Patto (1987), que faz uma retrospectiva da história da psicologia, ressaltando o caso da psicologia escolar, observa que "a psicologia nasce com a marca de uma demanda: a de prover conceitos e instrumentos 'científicos' de medida que garantam a adaptação dos indivíduos a nova ordem social" (a capitalista).(p.96)

O resultado destas e outras pesquisas demonstram que a sociedade tem demandado o psicólogo para atividades de ajustamento social, para aumento da eficiência dos indivíduos e do sistema. Surge daí, a preocupação com os instrumentos de medida que servirão para classificar, selecionar, reeducar e tratar. Ao responder a esse tipo de demanda, o psicólogo se compromete com a reprodução das relações instituídas e funciona como legitimador da desumanização do homem.

No entanto, observa-se que, paralelamente à demanda social tradicional segmentada em áreas - escolar, organizacional e clínica - tem ocorrido, no Brasil pós-ditadura militar, um processo novo de discussão sobre os modelos de atuação psicológica, realizado por algumas gestōes do Conselho Federal de Psicologia e Conselhos Regionais, Associações e Sindicatos da categoria em vários pontos do país e o Movimento Nacional de Saúde Mental. A luta antimanicomial, a participação dos psicólogos nas unidades de saúde, nos trabalhos sociais e comunitários e a assessoria a grupos populares, demonstram que novas possibilidades de atuação têm sido criadas, buscando responder a outros tipos de demanda anteriormente negadas.

$\mathrm{Na}$ medida que se rompe com as amarras da demanda tradicional, o espaço de atuação do psicólogo se amplia, novos empregos se abrem e o profissional necessita de uma visão de totalidade, capacidade de refazer a prática e não simplesmente trajá-la com novas cores recobrindo um mesmo conteúdo ${ }^{3}$. 


\section{Diversidade Teórica e Metodológica da Psicologia}

A diversidade teórico-metodológica da psicologia a fragmenta em concepções e práticas inconciliáveis. Várias tentativas de unificação e ecletismo têm sido realizadas sem sucesso, do ponto de vista da consistência teórica. As partes irredutíveis e aparentemente arbitrárias da psicologia, revelam, se contextualizadas, diferentes visões de homem e de sociedade possiveis em determinados momentos históricos. Patto (op.cit, p.87) considera a psicologia como "pseudociência"4 e utiliza uma citação de Deleuze (1972, p.47) para explicar que ela "longe de romper com a ideologia dominante, traz a esta última o apoio de seu aparato técnico e seu arcabouço teórico".

A saída que muitos psicólogos encontram para fugir à crítica e ao confronto de posições é a do fechamento dogmático nos seus referenciais teórico-práticos.

Existem várias psicologias, cada qual com seu desenvolvimento específico e discussões internas que merecem aprofundamentos, revisões e isolá-las ou unificá-las são tarefas que fragilizam a construção da ciência psicológica. Torna-se urgente conhecer a história da psicologia, com suas implicaçōes políticas, ideológicas e teóricas para desvendar suas crises no âmbito da vida social e cultural. Figueiredo (1991, p.206) diz:

"Uma história da psicologia (entendida como história dos conflitos, de suas origens na vida da sociedade e da cultura, de suas implicações teóricas, ideológicas e políticas), ainda por fazer, teria função essencial na formação do psicólogo e deveria ser contemplada em todos os currículos de graduação. Ela seria um instrumento de auto reflexão e auto conhecimento que contribuísse tanto para esclarecer ao futuro profissional o verdadeiro significado da dispersão e desconexão das disciplinas e orientações teóricas que enfrentou durante o curso, como fazê-lo entender o real alcance de suas opções. Se as diferentes matrizes refletem e expressam diferentes formas de relaçōes humanas, a opção individual entre correntes psicológicas é, em última instância, uma questão ética e não científica, mas não absolutamente uma questão para qual só existam soluçōes irracionais e arbitrárias".

Constituir essa história é ponto de partida para uma re-leitura da psicologia que contemple divergências. No entanto, o que vem ocorrendo é uma dispersão cada vez maior, com uma corrida alarmante dos psicólogos para alternativas pouco fundamentadas, que expressam, por um lado, desprezo pelo que aprenderam nas universidades, e por outro lado, uma busca de formas de oferecer ajuda psicológica que pareçam mais eficazes. Em uma sociedade em que o ser humano sofre restrições constantes a sua singularização, práticas que o levem a um mergulho em si mesmo podem trazer satisfação imediata, sensações de encontro com a felicidade $e$ com fragmentos perdidos na sua história de vida. Porém, a totalidade almejada é negada

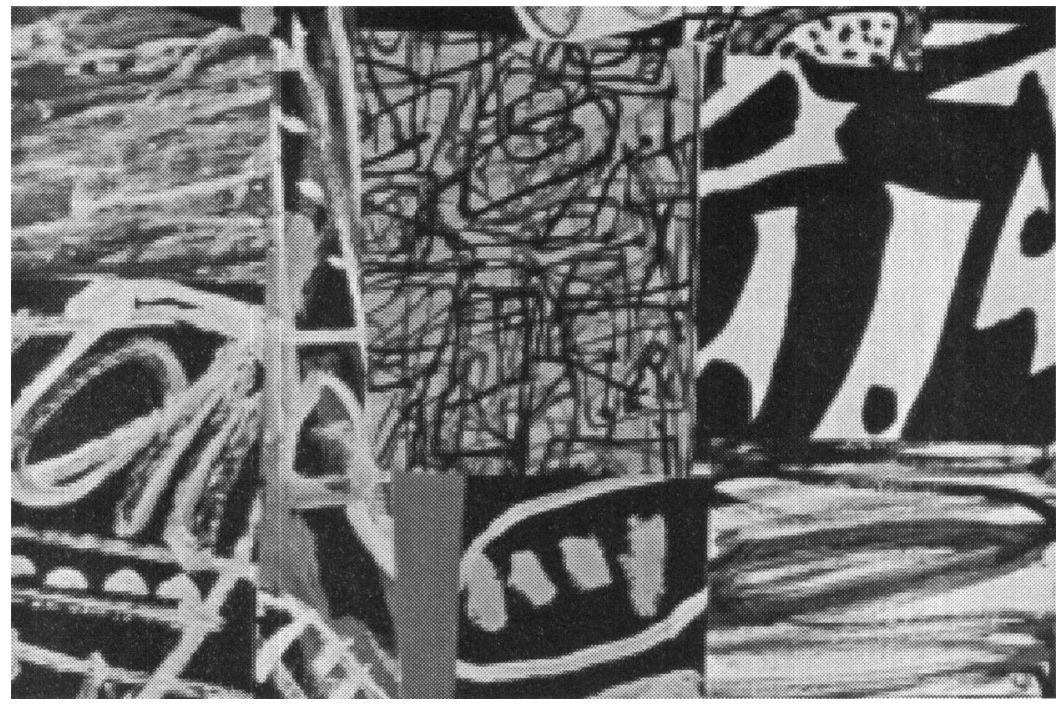

nas relações concretas e o mergulho em um si mesmo descolado do mundo engana-o, aliena-o, deixando-o no mesmo lugar, sem transformar o real, que faz parte da constituição da sua subjetividade; entregue ao instituído, viverá abstratamente sua "transformação pessoal". Muitas destas práticas alienantes fazem parte, hoje, do exercício profissional de inúmeros psicólogos.

Não é somente o ensino de uma história que permita a crítica às diferentes psicologias que fará esta pluralidade de concepções avançar como ciência e profissão. Além disso, a formação do psicólogo deve propiciar a
4. Patto utiliza o termo de Sastre: “ideologias que sendo regiōes diferenciadas da ideologia dominante. costumam ser reconhecidas socialmente como ciências". Sastre, C. (1974). La Psicologia. Buenos Aires. 
produção do conhecimento no processo de aprender, transformando a realidade, sistematizando e trocando idéias, através de materiais escritos pelos estudantes que gerem polêmica, re-estudos, novas elaborações. Teorias e práticas devem se articular. As implicações políticas, culturais e ideológicas das práticas devem se constituir como pontos de reflexão. Os professores devem se expor, explicitando o fundamento daquilo que ensinam e a inconsistência das teorias que estudam. Mais do que em qualquer campo do conhecimento, os especialistas precisam desenvolver uma visão de totalidade e romper com os limites de suas áreas, problema sério na psicologia. Patto (op. cit, p.95) recupera a história da constituição da psicologia nas três áreas tradicionais - escolar, clínica e organizacional - por onde se formam os especialistas, demonstrando como essa divisão foi fruto da demanda social das elites dirigentes:

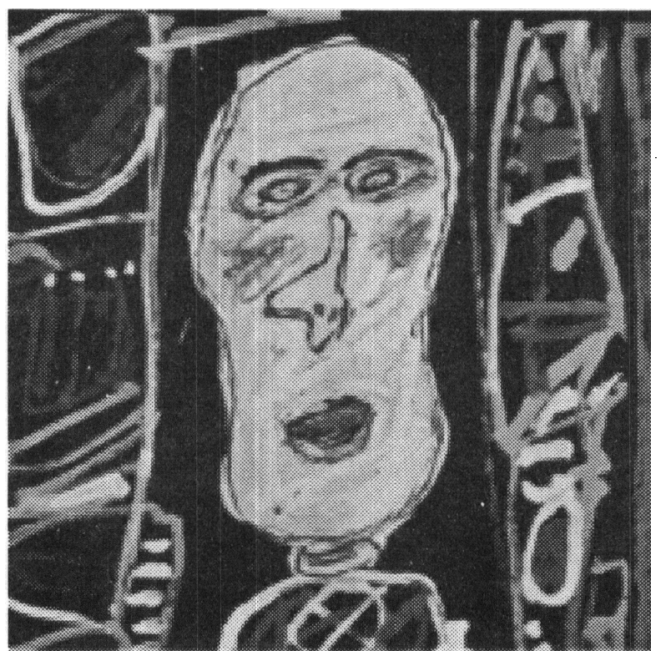

“(...) uma sociedade que necessitava (e ainda necessita) de instrumentos para selecionar, orientar, adaptar e racionalizar (...) No território da terapia as coisas não se passam de modo muito diferente; seu objetivo é a cura, simples processo de adaptação a normas que mantém o status quo e que têm como valores supremos a saúde, a maturidade e o êxito, assimilando amor e produtividade $\mathrm{e}$ baseando os valores culturais numa vasta harmonia que unicamente o indivíduo ... poderia romper".
A divisão em áreas aumenta a fragmentação do espaço psicológico, contribui para que os diferentes profissionais permaneçam surdos às demais tarefas que não se referem aos seus claustros. A Universidade reproduz essa circunstância e não reinventa uma formação sem áreas, onde o psicólogo não se defina por seu local de trabalho, mas por ser um profissional que ofereça ajuda psicológica em qualquer ambiente onde o homem atue. Trata-se de conhecer a atividade humana na sua totalidade, na sua historicidade, apreendendo a dimensão pessoal na dinâmica das relações sociais. Qual é o papel de um profissional de saúde mental? $O$ que seria saúde mental? E por que estas áreas na psicologia? Quem as definiu? Por que repetimos incessantemente essa divisão? $\mathrm{O}$ que estamos legitimando?

\section{Ensino Universitário no Brasil}

Conforme Fernandes (1989), a Universidade vive, há algum tempo, uma crise profunda, que não se expressa somente no desmantelamento de sua infra-estrutura material e desvalorização dos recursos humanos, mas também, na não produção do conhecimento, que ele chamou de "crise do saber". A reforma universitária de 1968 , no Brasil, direcionou a educação rumo a tecnocracia, para satisfazer a necessidade de implementar uma modernização que respondesse aos interesses do capital internacional. Importou-se "modos de fazer, viver e pensar modernos" que conviveram com estruturas de poder arcaicas e riqueza concentrada, determinando aumento da miséria da maioria dos brasileiros. A Universidade e instituições de pesquisa tiveram que oferecer suporte para esta modernização conservadora e "dolorosa", como foi chamada por Silva (1982). Ainda hoje, o neo-liberalismo dá continuidade aos mesmos planos, embora em nova conjuntura política.

O modelo de Universidade traçado visa a formação de tecnocratas bem preparados para as exigências de um mercado de trabalho escasso e competitivo. Quaisquer açōes que tentem romper com essa perspectiva sofrem inúmeras dificuldades, tanto do ponto de vista dos recursos materiais, como administrativos. 
A departamentalização dos cursos propiciou a formação de verdadeiros "feudos", dificultando o trabalho interdisciplinar de pesquisa e extensão. Geralmente, o cenário que se encontra é de cada professor realizando seu próprio trabalho individual, respondendo a interesses e relações pessoais, sem que este possa promover polêmica, reflexão e produção de um conhecimento coletivo.

Na formação do psicólogo, dada a diversidade teórica e metodológica da psicologia, a situação da Universidade cria obstáculos ainda mais difíceis de se transpor. A ciência psicológica, no estágio atual, exige pesquisa, extensão e ensino reflexivos, críticos e engajados. Como atender a esta exigência na formação do psicólogo?

\section{Síntese dos Três Aspectos}

O psicólogo que recebe o seu diploma após freqüentar, no mínimo, cinco anos de aulas na Universidadé, enfrenta: dispersão no campo do saber psicológico; fragmentação no processo de trabalho social realizado nas instituiçōes, além de falta de recursos materiais; ilusão de uma pseudo-autonomia do profissional liberal, almejada pela maioria no sonho do consultório particular; competição acirrada entre os próprios psicólogos, na corrida por emprego e posições nas instituições que os demandam e que são escassas; demanda por uma função adaptativa, corretiva re-educadora que lhe exigirá clareza do seu papel como psicólogo.

Várias pesquisas têm constatado que o psicólogo quando não trabalha em consultório tem grande dificuldade em definir sua identidade. Mello (1975) diz que muitos psicólogos não sabem caracterizar o que seria uma atividade clínica e encontra confirmação do resultado de sua pesquisa em Carvalho (1983), apresentados por Macedo (1984). Carvalho (op. cit.) demonstrou que em muitas circunstâncias onde o psicólogo estava registrado como tal, ele não sabia classificarse em nenhuma área e considerava ineficientes as técnicas que aprendeu na Universidade para o contexto onde atuava. O estudo sobre A Inserção dos Psicólogos nas Unidades Básicas de Saúde, realizado pelo
Conselho Regional de Psicologia 06, demonstrou que, além da dificuldade de definir o seu papel, recriar técnicas e encontrar os referencias teóricos adequados, o psicólogo, assim como outros profissionais das unidades básicas de saúde, não sabem trabalhar em equipe, compartimentando as açōes executadas junto a um mesmo sujeito.

Estes estudos nos fazem acreditar que o trabalho dos psicólogos, na maior parte dos locais onde atuam, deve estar ocorrendo de acordo com o que se espera deles: ações normalizadoras em relação à criança, ao adolescente, ao velho, ao louco e ao pobre que o impedirá de "escutar" a fala do outro e "enxergá-lo" como sujeito concreto, com uma história individual e social. Neste sentido, eles estariam atendendo ao mercado de trabalho que ainda requisita um profissional que remende os "malfeitos" da organizaçăo social. Esta constatação nos aponta que há necessidade de voltar a formação dos psicólogos não para atender às demandas do mercado, mas para um compromisso ético com o ser humano. Os serviços de promoção da saúde não podem ser vistos como uma mercadoria a ser consumida e os profissionais que atuam nesse campo não devem estar respondendo a relações mercadológicas.

Como diz Freire (1975), o compromisso de qualquer profissional com a sociedade é inevitável. Porém a sociedade não é homogênea, voltada para interesses comuns e para o "bem-estar"de todos. Assim, não há neutralidade possível. É preciso explicitar o compromisso - "com o quê?", "com quem"?

Que tipo de profissional queremos formar nos cursos de psicologia? Comprometido com a mudança ou com a legitimação das relações sociais? Especialista, tecnocrata ou conhecedor crítico das teorias psicológicas, produtor de conhecimento e agente de mudanças? Comprometido com o avanço da ciência psicológica ou amarrado ao dogmatismo de uma ou outra corrente do pensamento constituído? Preso às áreas específicas de atuação ou capaz de lidar com questões de saúde mental dentro de uma visão de totalidade da atividade humana? 


\section{Considerações Finais}

Não deve haver dúvida de que o profissional que pretendemos formar se comprometerá com a promoção da saúde. Para tal, não poderá legitimar as relações de violência instituídas na sociedade. A saúde envolve eliminação da fome, da miséria, da subnutrição, da ignorância e de qualquer forma de opressão. O compromisso do psicólogo só poderá ser com a mudança social.

Ele não deve ser um especialista, embora um estudioso permanente das situaçōes nas quais sua prática esteja implicada; deve desenvolver uma visão de totalidade, perceber as contradições inerentes a sua prática, ajudando aos grupos, indivíduos e instituições a eliminarem os processos de desumanização e alienação responsáveis pelo sofrimento psíquico.

A formação do psicólogo deve possibilitar o engajamento do futuro profissional na sociedade, além da re-elaboração do conhecimento constituído.

Para uma reformulação dos currículos dos cursos de psicologia não podemos pensar, apenas, numa nova listagem de conteúdos a serem ministrados. Devemos encontrar uma definiçāo de finalidades a partir das quais empreenderemos um trabalho contínuo de planejamento conjunto das atividades pedagógicas. Não devemos eliminar as diferenças teóricas e metodológicas, apesar das finalidades comuns. $O$ trabalho acadêmico coletivo deve explicitar e aprofundar as divergências. Além disso, a exigência por uma articulaçāo entre teoria e prática não poderá significar ativismo que diminua o estudo das teorias. Precisamos abarcar, de forma profunda, todas as matrizes do pensamento psicológico, em uma dinâmica de trabalho que permita o confronto de pontos de vista e projetos que reúnam vários campos do saber. A tradicional grade curricular por disciplinas, que fragmenta o conhecimento e o faz parecer produzido fora da vida, deve ser superada. A nova organização do currículo deve provocar a busca de soluções para problemas concretos e gerar a compreensão de que o conhecimento se constrói a partir das indagaçōes que o ser humano se faz e procura responder. Quais os problemas que a psicologia tem se proposto responder e quais procedimentos teórico-práticos têm se apresentado a partir de seus esforços? Quais os pontos que permanecem obscuros a partir das elaboraçōes já realizadas, ou que novas dúvidas puderam levantar? Que problemas a realidade brasileira coloca hoje para a psicologia e para os psicólogos? Que elementos podemos buscar em outros campos da ciência, da filosofia, das artes e do saber popular para problematizar o próprio campo constituído pela psicologia?
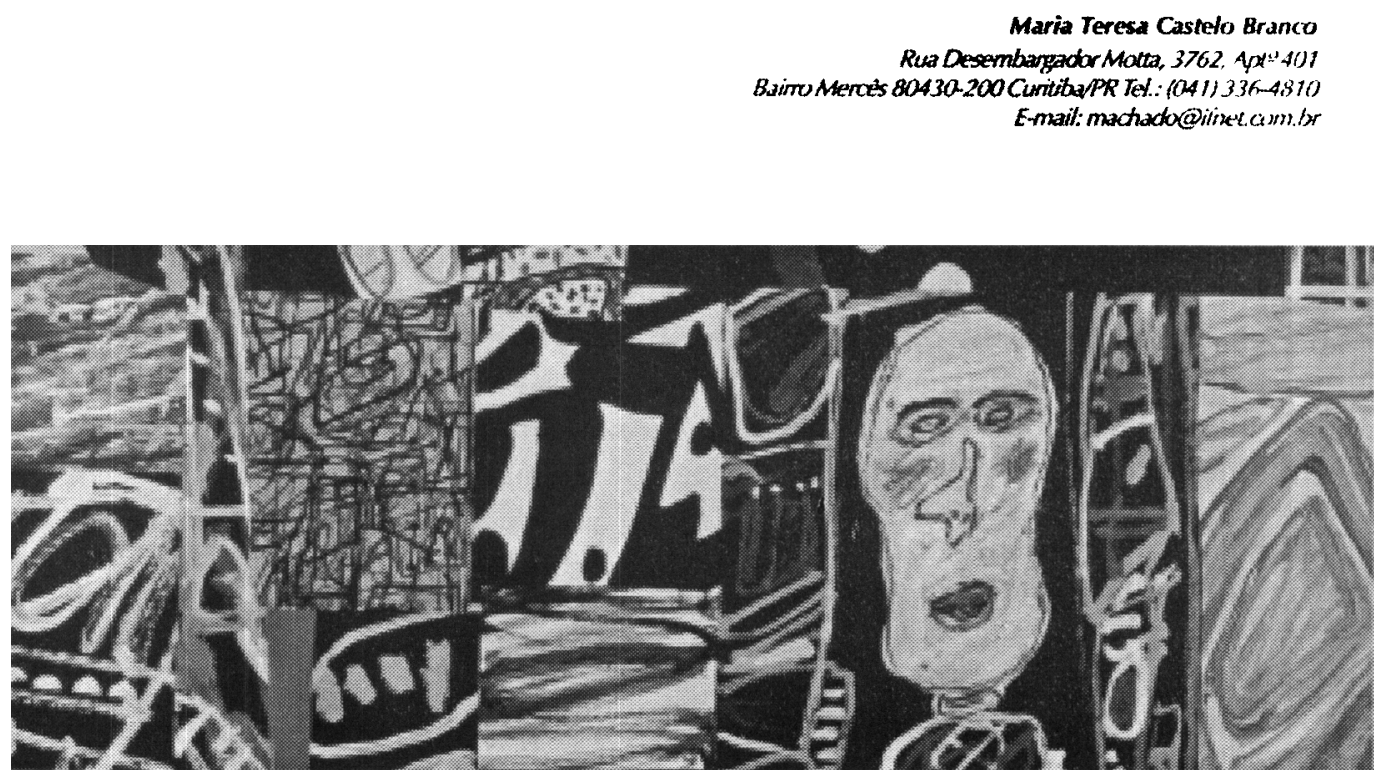
Buarque, C. (1991). Ocolapso da modernidade brasileira: e uma proposta alternativa. Rio de Janeiro: Paz e Terra.

Carvalho, A.M.A (1983). Modalidades alternativas de trabalho para psicólogos recém-formados. In: Simpósio sobre campos recentes em psicologia. SBPC, Be/ém, PA.

Deleuse, D. (1972). La psicologia, mito científico. Barcelona, Anagrama.

Fernandes, F. (1989). Odesafio educacional. São Paulo: Cortez.
Figueiredo, L.C.M(1991). Matrizes do pensamento psicológico. Rio de Janeiro: Vozes.

Freire, P (1975). Pedagogia do oprimido. Rio de Janeiro: Paze Terra.

Macedo, R.M. (Org.) (1984). Psicologia e instituiçăo: novas formas de atendimento. São Paulo: Cortez.

Mello, S.L (1975). Psicologia e Profissāo. São Paulo: Ática.

Patto, M.H.S (1987). Psicologia e ideologia. uma introduçāo crítica à psicologia escolar. São Paulo: TA; Queiroz editor.

Silva, J.G. da. (1982). A modemização dolorosa. Rio de Janeiro: Zahar.
Referências

bibliográficas 